\title{
Three-Dimensional Resultant Vibration Based on Hydraulic Excitation
}

\author{
Huixian Zhang ${ }^{1, *}$, Zhenmin Dong ${ }^{2}$ and Lingxia Miao ${ }^{1}$ \\ ${ }^{1}$ College of Mechanical Engineering, Luoyang Institute of Science and Technology, Luoyang 471023, China \\ ${ }^{2}$ Chongqing Academy of Metrology and Quality Inspection, Chongqing 401121, China \\ ${ }^{*}$ Corresponding author
}

\begin{abstract}
For studying a three-dimensional vibrating screen based on the fluid-filled pipe, a vibration testing system based on hydraulic excitation was established. The pressure wave generated from the vibration exciter will stimulate the pipe network to vibrate. The elastic plate served as the vibrating screen whose dynamic characteristics can be revealed by experiments. According to the measured signals, the twodimensional and three-dimensional resultant vibration trajectories were obtained. By comparison, the three-dimensional vibration trajectory is more complicated. Furthermore, served as the three-dimensional vibration screen whose screening efficiency is more higher, indicating that the three-dimensional vibrating screen based on the hydraulic excitation has been verified effectively. So we can conclude that a new vibration mechanism is found and this work is expected to serve for the optimum design of the hydraulic excitation system and play a guiding role to experimental research in future.
\end{abstract}

Keywords-hydraulic excitation; vibration exciter; acceleration transducer; resultant vibration

\section{INTRODUCTION}

For the mechanical and inertial vibrating screen, too much vibrating mass can cause difficulty adjustment process for vibration parameters. Due to many advantages, the hydraulic technology has been used into vibration machine widely. So, it has important theoretical and practical significance to study new hydraulic excitation mechanism and take it into vibration utilization. Paidoussis et al [1] studied instable regional and parametric resonance phenomenon of pulsating flow by the linear analysis and experimental methods. C Schmitt et al [2] established a numerical model to simulate the propagation of pressure waves in water, where the maximum pressure values resulting from water hammer has been estimated when closing valves in the network, and then the severity of a defect such as a corrosion crater (pit) has been estimated by computing a safety factor for the stress distribution at the defect tip. PerAnders et al [3] carried out finite element analysis for onedimensional fluid under the action of fluid structure interaction, and the transient response of free vibration of pipe was obtained by numerical simulation. Jiduo Jin et al [4] studied stability and parametric resonance of a clamped-clamped pipe conveying fluid. The results revealed the relationships between fluid and fluid-filled pipe, providing some theoretical foundation for stability design of pipe. Ridong Bao et al [5] studied dynamic characteristics of pipe conveying fluid with elastic support. The numerical results showed that its natural frequency is proportional to elastic supporting coefficient and axial pressed pressure. The static instability showed flow velocity varied conversely with elastic supporting coefficient, fluid pressure and axial pressed pressure, but varied with axial drawn pressure.

The studies above mostly concern how to reveal the damage factors of fluid-filled pipe, the ultimate aim is to provide some theory basis for hydraulic pipe design and to avoid it damaged. But only little research is presented on how to generate an active hydraulic excitation pressure by the fluidfilled pipe and to utilize it. Kou et al [6] studied the dynamic characteristics of the fluid in the hydraulic excitation system by the method of characteristics (MOC). Zhang et al [7] [8] developed a fluid-structure interaction model for the fluid-filled pipe, and the kinematic property of the pipe was simulated by the MOC and the finite element method (FEM). Evidently, some significative theoretical research has been carried out and some significant results have been obtained.

Therefore, for the purpose of revealing the dynamic characteristics of vibrating screen based on hydraulic excitation, in this study, we will build a vibration testing system, where a rectangular elastic plate served as the screen surface is fixed with the pipe. So, if we can find the motion characteristics of the elastic plate, then the vibration characteristics of vibrating screen based on hydraulic excitation can be obtained, thus the motion law of materials on the vibrating screen can be revealed.

\section{PRINCIPLE OF HYDRAULIC EXCITATION}

The developed hydraulic excitation system shown in Figure I consists of pump, hydraulic cylinder, vibration exciter, pipe network, rectangular elastic plate, axial spring and frequency converter, etc.Vibration exciter serves as a valve working from open to close rapidly, which is driven by motor and controlled by frequency converter, where there are three ports $\mathrm{A}, \mathrm{B}$ and $\mathrm{C}$ connected to the external pipe respectively. When the valve of the vibration excitation rotates to the position shown in Figure I(a), high pressure oil will flow into the hydraulic cylinder, then the piston will move downward until the valve rotates to the horizontal position $\mathrm{BC}$, at this moment the oil inlet $\mathrm{B}$ is closed and the piston reaches the bottom of cylinder.Once the valve rotates to the position shown in Figure I(b), the hydraulic cylinder will works in differential connection mode, and the piston will move upward until the valve rotates to the vertical position, then port $\mathrm{A}$ is 
closed and the piston reaches the top of the cylinder, consequently a vibration cycle is over. With rotating of the vibration exciter, the same motion will repeat periodically. As the valve's rotating, pulsating pressure wave from fluid between the hydraulic cylinder and the vibration exciter will stimulate the pipe network to vibrate.Thus, the elastic plate connected with the pipe network will also vibrate just like the vibrating screen. So, in comparison with the pure mechanical and inertial vibrating screen, it is obvious that their vibration mechanisms are different.

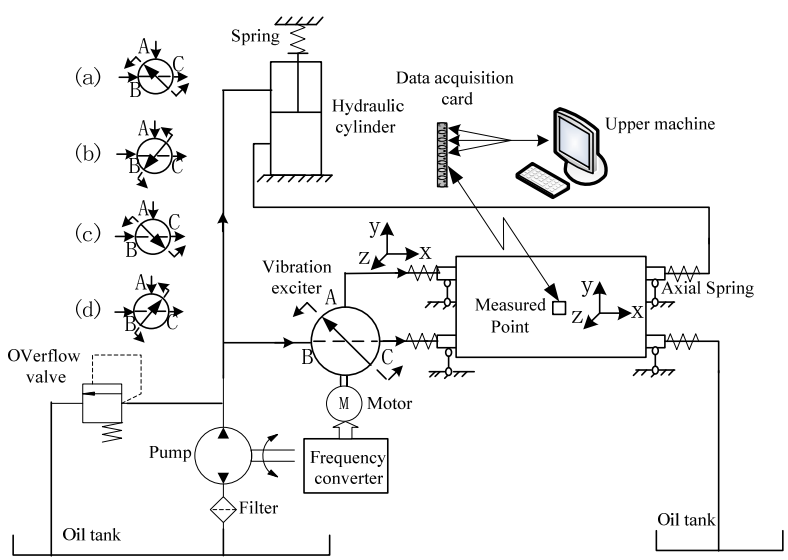

FIGURE I. SCHEMATIC DIAGRAM OF HYDRAULIC EXCITATION SYSTEM

The main design parameters of the developed hydraulic excitation system are as follows: where pipe length is $2000 \mathrm{~mm}$, its external diameter is $\Phi 34 \mathrm{~mm}$ and its wall thickness is $5 \mathrm{~mm}$; mid-diameter of axial spring is $\Phi 38 \mathrm{~mm}$ and its steel wire diameter is $\Phi 3.5 \mathrm{~mm}$; pump rated speed is $1500 \mathrm{r} / \mathrm{min}$, its rated pressure is $31.5 \mathrm{MPa}$ and its nominal discharge is $63 \mathrm{~mL} / \mathrm{r}$; power of frequency converter is $3 \mathrm{~kW}$ and vibration exciter motor is $1.5 \mathrm{~kW}$, its pole pairs is 3 .In addition, three-axis acceleration transducer is used for displacement amplitude measurement, and data acquisition card is used for signal collection.

\section{MEASURED Vibration SignaL}

By three-axis acceleration sensor and data acquisition card, the vibration testing for hydraulic excitation system is carried out, where the center of the elastic plate shown in Figure I is selected as the measured point whose vibration amplitude for $\mathrm{x}$, $\mathrm{y}$, and $\mathrm{z}$ axis are obtained. For reducing high frequency interference, the measured signal is filtered by least squares method. If the converter's frequency is set as $32 \mathrm{~Hz}$ and the pressure of hydraulic system is set as $4.5 \mathrm{MPa}$, then the timehistory curves of the measured signals and filtered signals for $\mathrm{x}$, $y$, and $z$ axis are presented in Figure II to Figure IV, where $x, y$, and $\mathrm{z}$ axis represent the axial direction, the transverse direction and the vertical direction respectively.

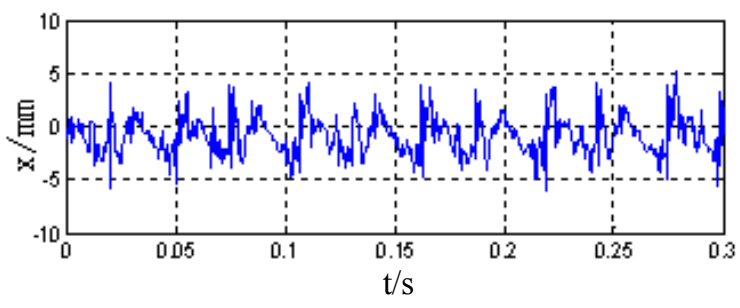

(a) MEASURED SIGNAL FOR X AXIS

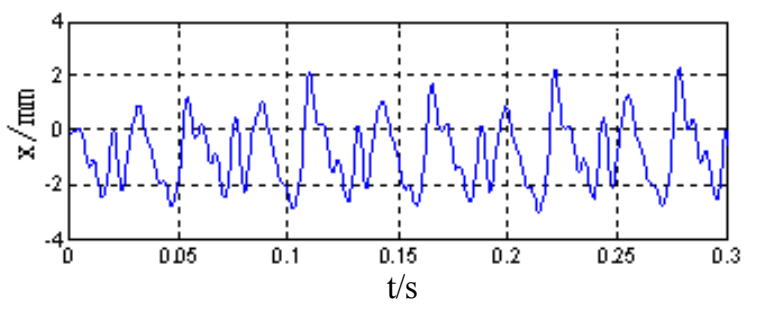

(b) FILTERED SIGNAL FOR X AXIS

FIGURE II. SIGNAL PROCESSING FOR X AXIS

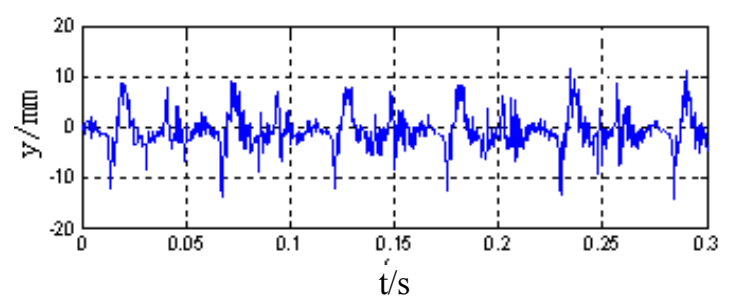

(a) MEASURED SIGNAL FOR Y AXIS

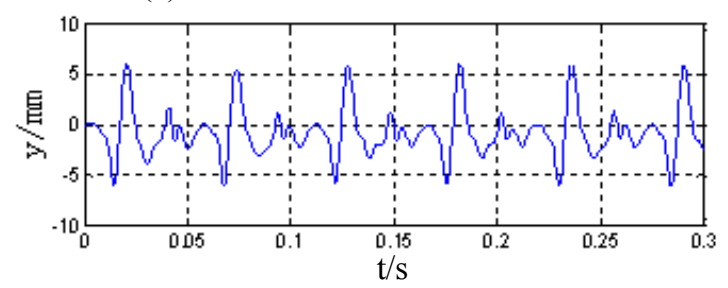

(b) FILTERED SIGNAL FOR Y AXIS

FIGURE III. SIGNAL PROCESSING FOR Y AXIS

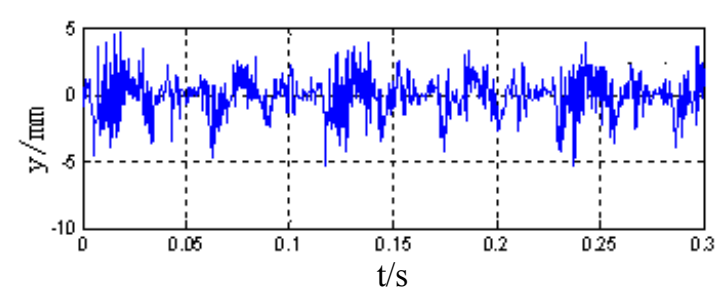

(a) MEASURED SIGNAL FOR Z AXIS

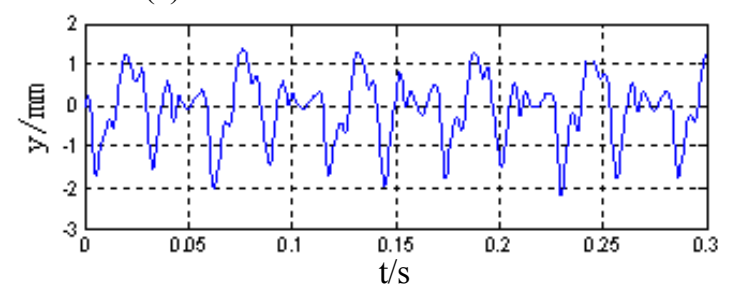

(b) FILTERED SIGNAL FOR Z AXIS

FIGURE IV. SIGNAL PROCESSING FOR Z AXIS 
It is obvious that high frequency disturbance of the signals are eliminated perfectly. Consequently, the filtered signals will be used to analyze the vibration characteristics of hydraulic excitation system. So, the two-dimensional resultant vibration are shown in Figure V(a),(b) and (c), corresponding to $x-y, y-$ $\mathrm{z}$ and $\mathrm{x}-\mathrm{z}$ plane. Evidently, the motion trajectories of twodimensional resultant vibration are complicated. Actually, the vibration of the hydraulic excitation system is threedimensional and multiple-degree-of-freedom. Therefore, to study the spatial vibration of the elastic plate is more practical. So, the three-dimensional resultant vibration of $\mathrm{x}, \mathrm{y}$, and $\mathrm{z}$ axis is obtained and shown in Figure VI.

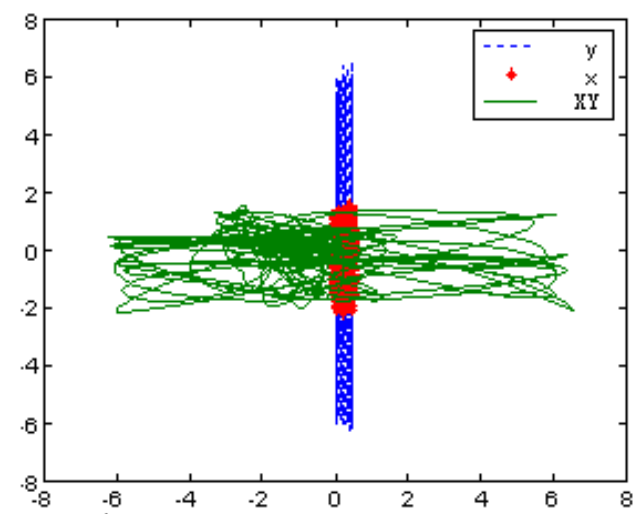

(a) X-Y PLANE

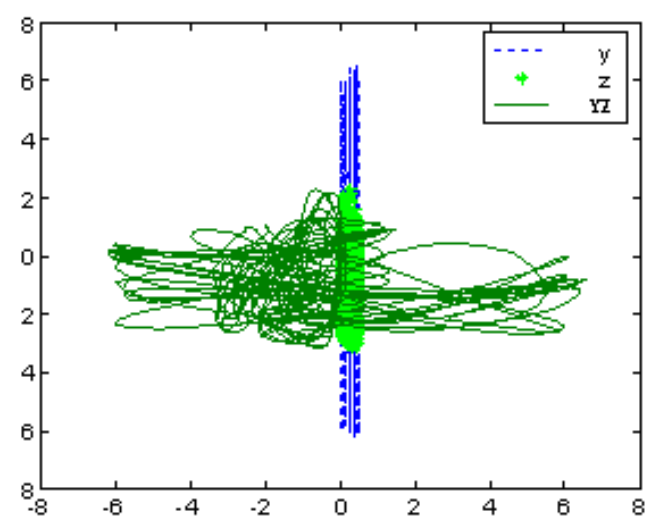

(b) Y-Z PLANE

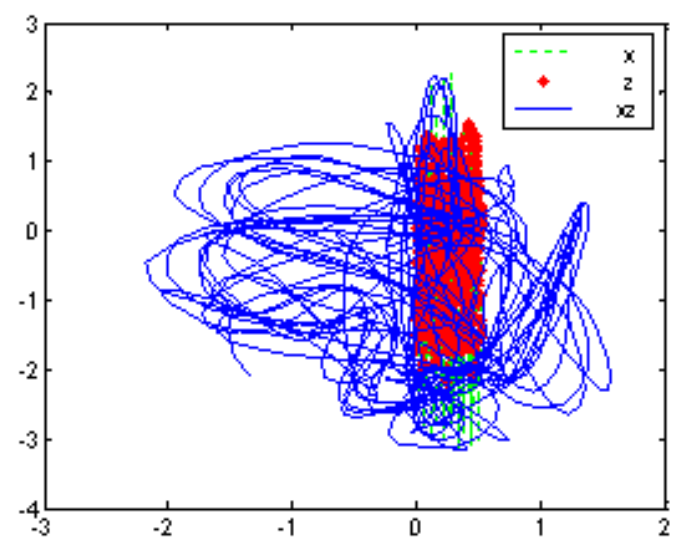

(c) X-Z PLANE

FIGURE V. TWO-DIMENSIONAL RESULTANT VIBRATION

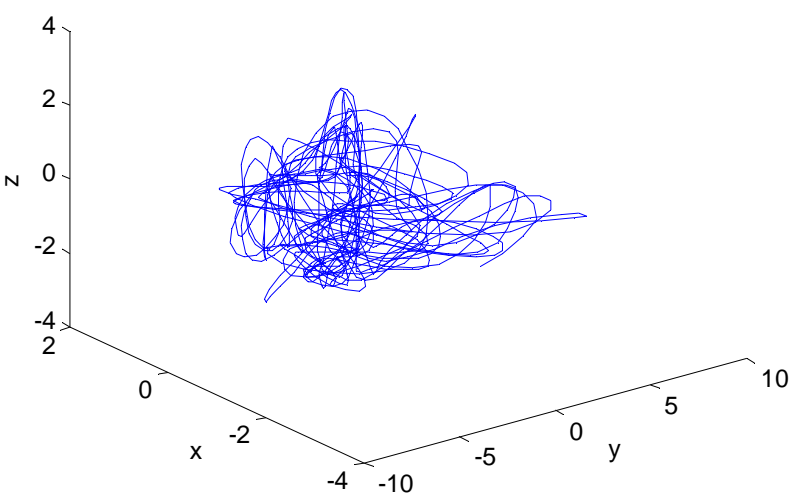

FIGURE VI. THREE-DIMENSIONAL RESULTANT VIBRATION FOR X, Y, AND Z AXIS

Figure VI shows the motion trajectories of threedimensional resultant vibration for $\mathrm{x}, \mathrm{y}$, and $\mathrm{z}$ axis is disorderly. In comparison with two-dimensional resultant vibration shown in Figure V, its vibration trajectory is more complicated, more importantly, its vibration trajectory is three-dimensional, which benefit materials to pass through the screening surface and can result in higher screening efficiency. As a result, we have demonstrated that the three-dimensional vibrating screen based on the hydraulic excitation has more advantages than that of two-dimensional planar vibrating screen.

\section{CONCLUSIONS}

(1) Aiming at some problems arising in mechanical inertial vibrating screen, a vibration testing system based on hydraulic excitation is established. The pressure wave generated from the vibration exciter will stimulate the pipe network to vibrate. The elastic plate is served as the vibrating screen fixed with the pipe, so the excitation from the fluid will stimulate the vibrating screen and whose dynamic characteristics can be revealed by experiments. Obviously, the vibration mechanisms are different from inertial vibrating screen. In this sense, the vibrating screen based on the hydraulic excitation is entirely new.

(2) Combing the experimental system, the vibration signals are measured and filtered. The two-dimensional and threedimensional resultant vibration trajectories are obtained. In comparison with two-dimensional resultant vibration, the threedimensional vibration trajectory is more complicated. Furthermore, served as the three-dimensional vibration screen, whose screening efficiency is more higher, indicating that the three-dimensional vibrating screen based on the hydraulic excitation has been verified effectively. So we can conclude that a new vibration mechanism is found and which can make an attractive result.

\section{ACKNOWLEDGMENT}

The project is supported by The National Natural Science Foundation of China (U1404513).

\section{REFERENCES}

[1] Paidoussis M P, Issid N T.Experiments on parametric resonance of pipes containing pulsatile fluid [J]. Applied Mechanics, 1976,43:198-202. 
[2] C.Schmitt, G.Pluvinage. Water pipeline failure due to water hammer effects [J]. Fatigue and Fracture of Engineering Materials and Structures, 2006,29(12): 1075-1082

[3] Per-Anders Hansson.Göran Sandberg.Dynamic finite element analysis of fluid-filled pipes [J].Computer Methods in Applied Mechanics and Engineering,2001,190: 3111-3120.

[4] JIN Jiduo, SONG Zhiyong, YANG Xiaodong.Stability and parametric resonances of a clamped-clamped pipe conveying fluid [J]. Journal of Vibration Engineering,2004,17(2):190-195.

[5] BAO Ridong, JIN Zhihao, WEN Bangchun (2008) Analysis of nonlinear dynamic characteristics of commonly supported fluid conveying pipe. Journal of Vibration and Shock 27(7):87-90.

[6] KOU Ziming, ZHANG Huixian, LIAN Hongzhen, et al. Design and simulation of an active hydraulic excitation system based on frequency conversion[J]. Transactions of Chinese Society for Agricultural Machinery, 2011,42(5):226-230.

[7] ZHANG Huixian, KOU Ziming, Wu Juan, et al. Dynamic Modeling and Experiments for Fluid Structure Interaction in Pipe under Hydraulic Shock Wave [J].Journal of Xi'an Jiaotong University, 2012,46(3):94-99.

[8] ZHANG Huixian, KOU Ziming, Lu Chunyue, et al. Kinematic Analysis and Experimental Research of Pipe Vibration Control Based on an Active Hydraulic Excitation Force [J]. Journal of Mechanical Engineering, 2012, 39(2): 94-99 